WellBeing International

WBI Studies Repository

2010

\title{
Octopuses (Enteroctopus dofleini) Recognize Individual Humans
}

\author{
Roland C. Anderson \\ The Seattle Aquarium \\ Jennifer A. Mather \\ University of Lethbridge \\ Mathieu Q. Monette \\ University of Brussels \\ Stephanie R.M. Zimsen \\ The Seattle Aquarium
}

Follow this and additional works at: https://www.wellbeingintlstudiesrepository.org/acwp_asie

Part of the Animal Studies Commons, Comparative Psychology Commons, and the Other Animal Sciences Commons

\section{Recommended Citation}

Anderson, R. C., Mather, J. A., Monette, M. Q., \& Zimsen, S. R. (2010). Octopuses (Enteroctopus dofleini) recognize individual humans. Journal of Applied Animal Welfare Science, 13(3), 261-272.

This material is brought to you for free and open access by WellBeing International. It has been accepted for inclusion by an authorized administrator of the WBI Studies Repository. For more information, please contact wbisr-info@wellbeingintl.org.

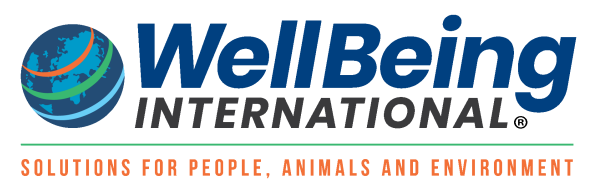




\title{
Octopuses (Enteroctopus dofleini ) Recognize Individual Humans
}

\author{
Roland C. Anderson, ${ }^{1}$ Jennifer A. Mather,${ }^{2}$ Mathieu Q. Monette, ${ }^{3}$ and Stephanie R. M. Zimsen ${ }^{1}$ \\ ${ }^{1}$ The Seattle Aquarium \\ ${ }^{2}$ University of Lethbridge \\ ${ }^{3}$ University of Brussels
}

\begin{abstract}
This study exposed 8 Enteroctopus dofleini separately to 2 unfamiliar individual humans over a 2-week period under differing circumstances. One person consistently fed the octopuses and the other touched them with a bristly stick. Each human recorded octopus body patterns, behaviors, and respiration rates directly after each treatment. At the end of 2 weeks, a body pattern (a dark Eyebar) and 2 behaviors (reaching arms toward or away from the tester and funnel direction) were significantly different in response to the 2 humans. The respiration rate of the 4 larger octopuses changed significantly in response to the 2 treatments; however, there was no significant difference in the 4 smaller octopuses' respiration. Octopuses' ability to recognize humans enlarges our knowledge of the perceptual ability of this nonhuman animal, which depends heavily on learning in response to visual information. Any training paradigm should take such individual recognition into consideration as it could significantly alter the octopuses' responses.
\end{abstract}

Many mammals and birds can recognize individual humans. Dogs, for example, not only can recognize people visually and olfactorily (Adachi, Kuwahata, \& Fujita, 2007) but also can even distinguish between their gestures (Soproni, Miklosi, Csanyi, \& Topal, 2001). Other mammals (Davis, 2002) and birds (Davis, 2007b; Marzluff \& Angell, 2005) have been able to distinguish between humans. Domestic ungulates such as cows and pigs can recognize individual handlers and react differently to different handlers (Boivin, Garel, Mante, \& LeNeindre, 1998; Koba \& Tanida, 2001; Rousing, Ibsen, \& Sørenson, 2005; Rybarczyk, Koba, Rushen, Tanida, \& de Passillé, 2001). Nonhuman animals such as chimpanzees (Boysen, 1994), dogs (Adachi et al., 2007), and squirrel monkeys (Adachi \& Fujita, 2007) use multiple modes of recognition such as visual and auditory means.

The generality of human recognition abilities in invertebrates is unclear. Recently, Davis (2007a, 2007c) has found some insects (honeybees and cockroaches) also able to recognize individual humans, presumably using olfaction. Even in the wild, when the relationship is not so close, some animals can distinguish individual humans. For instance, corvids in the wild can tell individual humans within a crowd who have caught them for banding (Lorenz, 1952; Marzluff \& Angell, 2005). However, there is a huge gulf between the many vertebrates who have been documented to recognize humans and the few invertebrates who have been reported to do so.

Octopuses would appear to be appropriate animals in whom to look for the ability to distinguish between individual humans. Octopuses are in a different phylum from insects or vertebrates and are 
acknowledged as the most intelligent invertebrate (Anderson, 2005; Hochner, Shamrat, \& Fiorito, 2006); octopuses are capable of many types of learning (Mather, 1995). Octopuses are known for their memory of visual patterns (Wells, 1978) and can learn to discriminate between abstract shapes (Sutherland \& Carr, 1963; Young, 1956). Octopuses can also learn by conditioning (Angermeier \& Dassler, 1992; Crancher, King, Bennett, \& Montgomery, 1972; Papini \& Bitterman, 1991) and can change their colors and patterns rapidly in response to conditioning (Warren, Schieier, \& Riley, 1974). They may even be able to learn by observation of the behavior of other octopuses (Fiorito \& Scotto, 1992). This indicates they also may be able to process visual events outside their tanks. Giant Pacific octopuses (Enteroctopus dofleini ) are kept in many public aquariums (Carlson \& Delbeek, 1999), giving them the opportunity for both visual recognition of individual keepers and rewarding and aversive consequences of interactions. They are also the subject of increasing research (Anderson \& Mather, 2007; Mather \& Anderson, 2007) on their cognitive capacity; hence, they should be good subjects in whom to look for human recognition.

Obviously, responses that might indicate recognition of individual humans will not be the same as those used for vertebrate subjects. However, octopuses have been easily conditioned to move toward a positive visual stimulus in a learning paradigm (Wells, 1978); although octopus movement will be constrained by the boundaries of water and the tank, such movement should be applicable here. Another measure that has been recorded when octopuses are "irritated" is the aiming of jets of water through the funnel at the stimulus, reported for octopuses in the wild in Bermuda by Mather (1992) and well known by aquarium keepers. Boyle (1983) suggested that respiration rate in octopuses is a valid measure of their arousal, which he saw when they were exposed to chemical cues. This measure was also used by Wells, O'Dor, Mangold, and Wells (1983), Chase and Wells (1986), and Sinn, Perrin, Mather, and Anderson (2001) to show irritation by octopuses. A final measure of "response to disturbance" is changes in skin patterns and color. During such situations in testing, Packard \& Sanders (1971) reported what they described as conflict mottle, accompanied by dark Eyebars. Such bars are commonly seen as extensions of the horizontal dark pupil and, as there are several skin chromatophore fields around the eye (Leite \& Mather, 2008), can display a vivid and specific pattern.

Various researchers have casually mentioned an octopus's ability to recognize humans. Dews (1959) reported one animal who continually jetted water at the researcher rather than performing a leverpressing response. Anderson (2005) described an octopus who jetted water only at a particular night guard. Anderson \& Martin (2002) reported an octopus on display at the Point Defiance Aquarium who, perhaps expecting food, would move toward the keeper among a crowd surrounding the tank. To systematize and validate such observations, we noted giant Pacific octopuses' (Enteroctopus dofleini ) responses to visual exposure of individual humans who treated the octopuses differently. We predicted that they could learn to distinguish between specific humans. We discussed the effects such possible recognition in an intelligent invertebrate commonly kept in captivity might have on the animal's behavior with humans during routine husbandry tasks or research projects.

\section{MATERIALS AND METHODS}

Eight giant Pacific octopuses of differing sizes (Enteroctopus dofleini; mean $16.7 \mathrm{~kg}$, range 2.6-36.4 kg, SD $14.6 \mathrm{~kg}$ ) were captured at Seaside (Oregon State) or Neah Bay (Washington State). The sizes varied simply because of the low availability of this species; these were the animals available for testing. They were transported to the Seattle Aquarium per Anderson (1997). The four larger ones were installed in tanks $1.3 \mathrm{~m}$ square with water $1 \mathrm{~m}$ deep and the four smaller into smaller aquariums $(1.0 \times 0.67 \times 0.5 \mathrm{~m}$ with $0.5 \mathrm{~m}$ water depth). The octopus containers were covered with a wooden lid and, upon start of the experiments, an opaque black plastic sheet was placed over the front glass of the aquariums to prevent the octopus from seeing other humans. Seawater supplying the tanks was pumped from Puget Sound 
and filtered through sand and gravel filters. Temperature of the water averaged $10^{\circ} \mathrm{C}$, oxygen level was 7-8 ppm, and $\mathrm{pH}$ was 7.8.

The octopuses were fed thawed frozen herring twice daily (morning and afternoon) during the course of the study. They were not fed during the 2-day break in the testing schedule. Before the experiments started, the subjects were fed daily by an unseen volunteer who was not involved in testing so that the octopuses had not seen the experimenters prior to testing. The testers were R.A., M.M., and S.Z. Six of the octopuses were tested by exposure to R.A. and M.M., and two were tested by R.A. and S.Z. The testers dressed identically in a blue aquarium uniform shirt. However, there were obvious physical differences in their appearance, such as length and color of hair or mustache, shape of the face, and body build (Figure 1). To assure inter-observer reliability the three testers practiced making observations on a non-test animal.

During the course of the study, octopuses were fed by one tester and mildly irritated by another. Irritation was done by touching the octopus with a bristly stick for $30 \mathrm{~s}$; the stick was a length of PVC pipe with one end wrapped with Astroturf. The same human consistently fed a particular subject throughout all trials; the other person consistently irritated that subject. For each trial, each tester first opened the tank so that the octopus could see the person and recorded the animal's initial behavior, including color, skin texture, movements, inking, blowing water toward a person, the funnel direction (to or away from the tester or to the side), presence or absence of an Eyebar, or other behaviors, using "all-occurrence" sampling (Figure 2). The tester also measured respiration period, that is, length of time to take 10 full breaths. Then each tester either fed or irritated the octopus and recorded changes in behavior. Ten minutes after the first trial, the second tester conducted a second trial, interacting with the octopus and recording responses. The order of presentations and humans was determined each day by a series of random numbers, assigning a food presentation and a human. These exposures were given once in the morning and once in the afternoon at least $4 \mathrm{hr}$ apart for 5 days, followed by a 2-day break with no feeding and no human interaction; the treatment was repeated for 5 more days. After this regimen, in a follow-up on the 11th day, each person just looked in the tank and recorded octopus reactions, 10 min apart, reversing the order of human presentation with each octopus.

Some of the behaviors recorded had a wide range of possible responses, which were combined to facilitate analysis. For example, moving toward or reaching one or two arms toward a tester was counted as a movement toward. Moving downward or toward the back of the tank was counted as a movement away. Remaining still or pacing back and forth across the front glass of the tank was counted as a neutral movement. Relevant behaviors are recorded in Table 1.

Appropriate statistical analyses were then performed on the responses (Zar, 1996), using the program JMP (SAS Institute, Version 7, 2007) and an alpha level of 0.05 . The statistical analyses used for each treatment are cited in the text as they are used. When possible, we compared responses between treatments during the first and the final trial. Frequently there were few data points among all octopuses in these initial and final trials as not every behavior was performed by every octopus at every trial. When there were insufficient data for the use of informative statistics from all initial and final trials, we compared naive responses during "early" trials (the first 4 trials in the first 2 days) and "late" ones during the 2nd week (Trials 11-21).

No octopuses were harmed during the course of this study. Although mildly irritated by the bristly stick, octopuses' skin was not injured. After testing, octopuses were put on exhibit at the Seattle Aquarium or the Seaside Aquarium. 
FIGURE 1 An underwater view of Roland and Matt. Octopuses (Enteroctopus dofleini) could tell the difference between the two humans. It is unknown how octopuses see their world, but they do have excellent vision. Photo courtesy of Veronica von Allwörden.

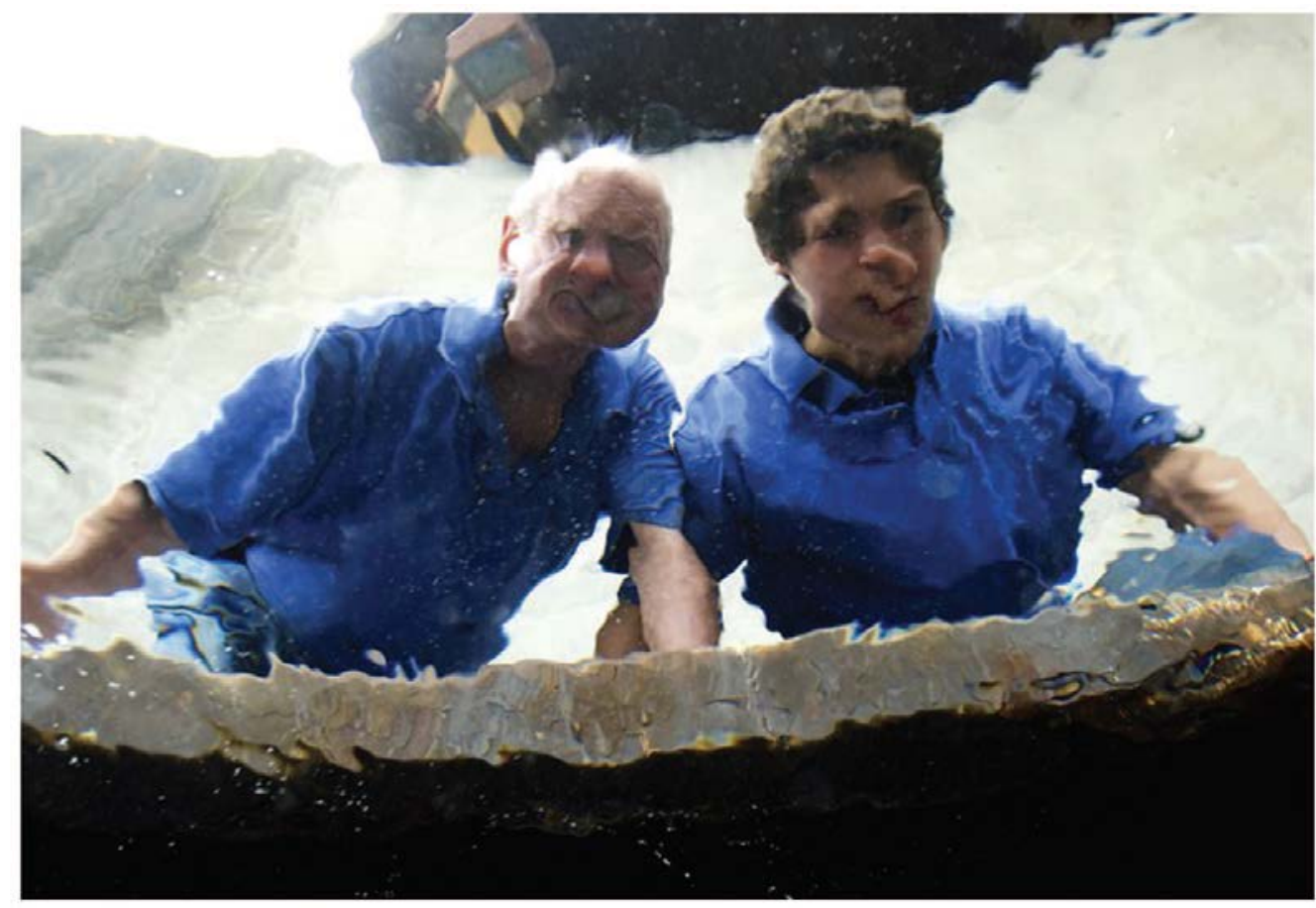

FIGURE 2 Photo of an octopus (Enteroctopus dofleini ) in the wild showing the display of "Eyebar," which may be a response to an irritant. The Eyebar is aligned in front and behind the eye with its horizontal pupil (see arrow). Photo courtesy of Veronica von Allwörden.

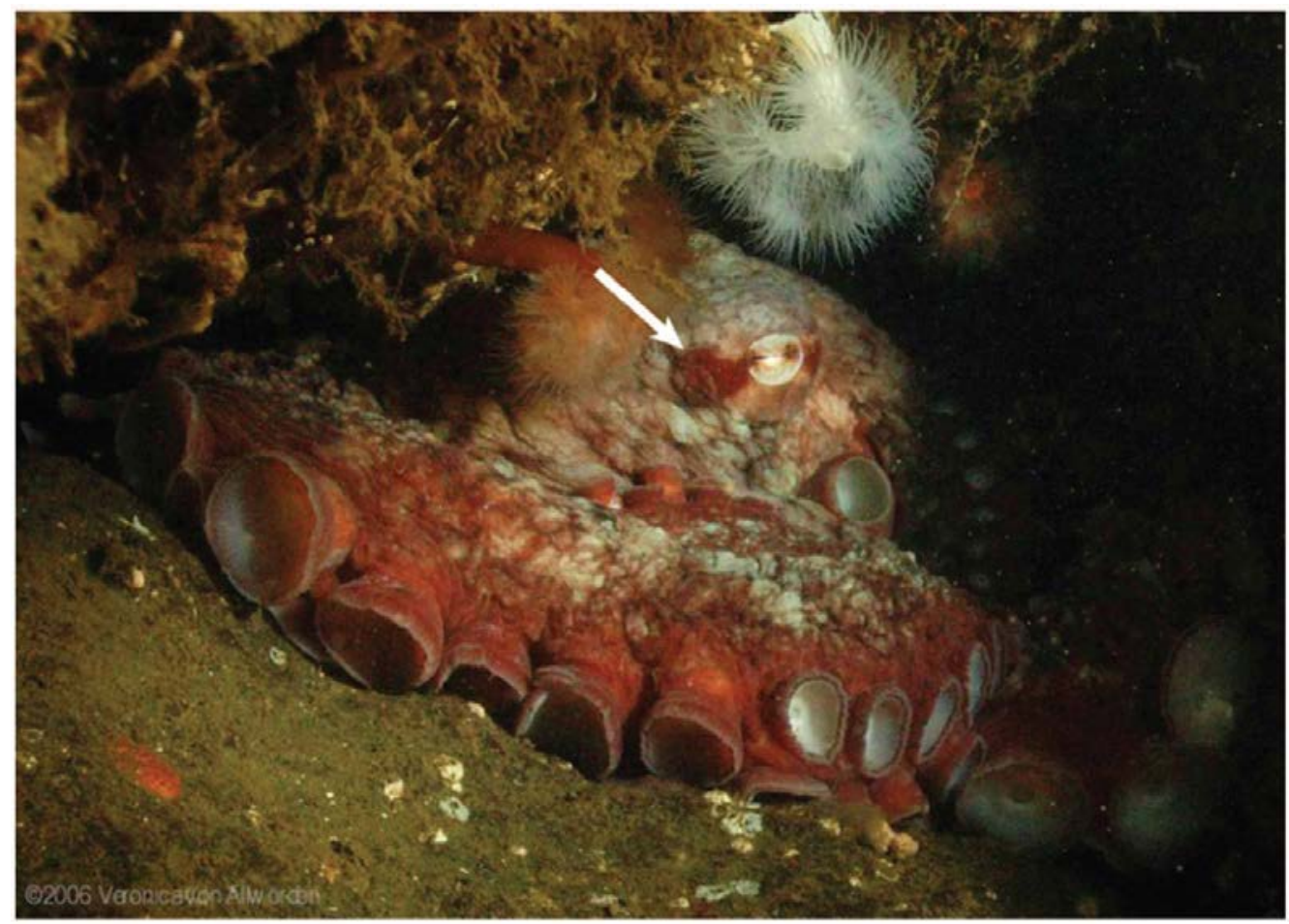


TABLE 1 Relevant Behaviors of Octopuses (Enteroctopus dofleini) That Were Observed During the Course of This Study

\begin{tabular}{|ll|}
\hline Behavior & Description \\
\hline Tuck & Animal is still, with arms folded together touching the body \\
Reach & Animal is still, with arms extended and spread out \\
Crawl & $\begin{array}{l}\text { Animal is still but extends out one or two arms toward an item of interest: } \\
\text { toward water surface, toward food, toward a human }\end{array}$ \\
Using arms to move body by extending arms, attaching suckers to the \\
substrate and pulling body forward
\end{tabular}

\section{RESULTS}

By the end of testing, four responses stood out as differing between feeders and irritators: direction of movement, a dark Eyebar body pattern, direction of funnel aiming, and respiration period. Other behaviors were not significantly different between feeders and irritators or had frequencies too low for testing.

\section{Movement}

An octopus typically moved neutrally with respect to the tester, neither toward nor away: during the 2nd week, $80 \%$ of movement responses were either holding still or pacing back and forth across the front of the aquarium (the remaining $20 \%$ being movement toward or away from the tester). During the first 4 trials, octopuses primarily moved away from testers, with no discernible difference between treatments (Fisher's exact test, one-tailed, $p=.45, n=17$ movements). During the 2nd week, however, octopuses usually moved toward feeders (13 of 14 trials) and away from irritators ( 5 of 11 trials; Fisher's exact test, one-tailed, $p<.05, n=25$ movements).

\section{Presence or Absence of an Eyebar}

There was no detectable difference between the appearance of an Eyebar display in response to feeders and irritators in the initial trial (Fisher's exact test, one-tailed, $p=.95, n=6$ Eyebars); however, in the final 
trial, octopuses who saw their feeder displayed Eyebars less frequently than those who saw their irritator (Fisher's exact test, one-tailed, $p<.0001, n=15$ Eyebars).

\section{Direction of Funnel}

During the final trial, octopuses aimed their funnels and water jets mostly away from feeders (aiming toward feeders in only 1 of 8 trials) and usually aimed toward irritators (6 of 8 trials). These responses were significantly different toward feeders versus toward irritators (Fisher's exact test, one-tailed, $p<.0001)$.

\section{Respiration Rate}

Respiration rates of individual octopuses seeing their feeder versus irritator were compared over the entire trial period; overall significance was adjusted for the eight multiple comparisons. The four larger animals each had longer breathing periods (thus slower breathing rates) when seeing feeders than irritators ( $t$ tests, $p<.0005$, with Bonferroni-adjusted $\alpha=0.00625$ ). None of the four smaller animals with shorter breathing periods (and thus faster respiration rates) exhibited significant differences between treatments ( $t$ tests, $p>.1$, with Bonferroni-adjusted $\alpha=0.00625$ ).

In order to test early versus late responses, we grouped animals by size as mentioned earlier and tested whether groups had different mean breathing rates in response to feeders versus irritators, at naive versus experienced phases of the experiment (Table 1). For the group of four smaller octopuses, breathing rates were not significantly different when facing their feeder versus irritator in either phase. During the first four trials, large octopuses also had similar mean breathing rates when facing feeders versus irritators. But by the last week of testing, large octopuses on average did have a faster breathing rate when facing their irritator (Table 2).

TABLE 2 Mean Respiration Rate of Octopuses (Enteroctopus dofleini ; $\boldsymbol{n}=\mathbf{8}$ )

\begin{tabular}{|c|c|c|c|c|c|c|}
\hline \multirow[b]{2}{*}{ Size } & \multicolumn{3}{|c|}{ Early (First 4 Trials) } & \multicolumn{3}{|c|}{ Late (Last 4 Trials) } \\
\hline & $\begin{array}{l}\text { Response } \\
\text { to Feeder }\end{array}$ & $\begin{array}{l}\text { Response } \\
\text { to Irritator }\end{array}$ & $\Delta$ & $\begin{array}{l}\text { Response } \\
\text { to Feeder }\end{array}$ & $\begin{array}{l}\text { Response } \\
\text { to Irritator }\end{array}$ & $\Delta$ \\
\hline Small & 10.8 & 11.7 & ns & 10.6 & 11.6 & ns \\
\hline Large & 6.8 & 7.6 & $n s$ & 5.7 & 7.5 & ns \\
\hline \multicolumn{7}{|c|}{$\begin{array}{l}\text { Note. Responses are in respirations per minute. Only in the four larger octopuses and only after a week } \\
\text { of experience did respiration rates differ in response to seeing feeders and irritators (see text). } \\
\text { Differences }(\Delta) \text { : } n s=\text { nonsignificant. }\end{array}$} \\
\hline
\end{tabular}

\section{DISCUSSION}

Because octopuses have good visual acuity (Boal, 2006; Hanlon \& Messenger, 1996;Muntz \& Gwyther, 1988), it is logical that they could discriminate between humans on the basis of these cues. Other experiments have found octopuses capable of fine visual discrimination (Hvorecny et al., 2007; Wells, 1978). Boal proved that an octopus has the memory capacity, both short and long term, to remember the effects of such visual discrimination tests. 
The presence or absence of a dark Eyebar in the octopuses was interesting. Octopuses produced Eyebars when facing their irritator, so the Eyebar may be a body-pattern response to potential threat or irritation. Eyebar as a body pattern has been described in octopuses (Leite \& Mather, 2008; Packard \& Sanders, 1971); however, the circumstances of its use have not yet been investigated. Packard and Sanders described it as a component of the "conflict mottle" (1971, p. 783). in response to disturbance. In other cephalopods, a similar body pattern called Deimatic-shown by dark eye rings, blotches, or false eye spots (ocelli)—is produced under conditions of mild threat (Hanlon \& Messenger, 1996; Moynihan \& Rodaniche, 1982; Muntz \& Gwyther, 1988).

Permanent Eyebars in other animals may provide camouflage of the very visible eye during attack by a predator (Coss \& Goldthwaite, 1995; Cott, 1940). Further work is obviously necessary to illuminate the use of such body patterns in octopuses.

We expected a difference in the respiration rate between the feeder and the irritator, but this was not always the case here. Generally, octopus respiration rate increases during feeding or at the expectation of feeding (Boyle, 1983), and changes in respiration rate may be a quantifiable measure of arousal in octopuses (Boyle, 1983). The four larger octopuses had a difference in respiration rate between the two treatments whereas the four smaller ones did not. There are several factors that may explain these differences. Large animals are more experienced and hence may learn better or see better. This is obviously a realm for further study.

Octopus recognition of individual humans adds another capacity to their already substantial repertoire of cognitive abilities. These are animals who can play, using modulated water jets to blow a floating object around a tank (Mather \& Anderson, 1999); have personalities (Mather \& Anderson, 1993); can be both classically and operantly conditioned (Young, 1956); and have spatial as well as procedural memory and good visual acuity and chemical sensing (Mather, 2008). But what use would it be for octopuses to recognize individual humans? They are not social (Boal, 2006). It must be a result of their excellent pattern recognition, tested in the 1950s and 1960s (Wells, 1978). For an animal who could discriminate vertical and horizontal extents of stimuli, circles from squares, and figures with different edge/area ratios, discriminating two quite different-appearing humans must not have been difficult. Still, as octopuses do not generally forage using visual cues (Mather, 1991), this leaves the question of for what purpose their excellent vision has evolved. Perhaps it is selected in part for situations such as this one: to discriminate different hetero-specific individuals and tell the threatening from the harmless inhabitants of their environment.

Regardless of the evolutionary background of this capacity, which remains to be studied, the ability of octopuses to recognize individual humans should give both aquarium personnel and researchers pause.

\section{CONCLUSION}

Giant Pacific octopuses are commonly held in captivity in public aquariums (Anderson, 1997; Carlson \& Delbeek, 1999). That the octopuses can remember how individual people treated them should be part of information provided to handlers. They may not learn in a single trial as do corvids, who avoid or mob individuals who have captured and handled them (Lorenz, 1952; Marzluff \& Angell, 2005). Octopuses, however, will remember "annoying" people and soak them with water jets (Anderson \& Martin, 2002; Dews, 1959). They might avoid irritators and not accept food during public demonstrations or tests of intelligence, depending on who is conducting them. It is important for researchers who might wish to condition respiration rates or measure skin displays to know that individual recognition of testers might mean that the response rates were already altered. 
That octopuses can recognize individual humans is one more reminder that scientists and keepers form what Davis and Balfour (1992) described as "the inevitable bond" (p. 3) with their animals, that there is more going on in these interactions than just provision of food or presentation of stimuli for testing. They described the bonding process as a relationship between the observer (a person) and the observed (animal), although they note the relationship is two-way. Our results are a reminder that such a relationship may form between pairs as phylogenetically distant as humans and octopuses.

\section{ACKNOWLEDGMENT}

We thank the staff and volunteers of the Seattle Aquarium for supplying octopuses and holding facilities.

\section{REFERENCES}

Adachi, I., \& Fujita, K. (2007). Cross-modal representation of human caretakers in squirrel monkeys. Behavioural Processes, 74, 27-32.

Adachi, I., Kuwahata, H., \& Fujita, K. (2007). Dogs recall their owner's face upon hearing the owner's voice. Animal Cognition, 10, 17-21. Anderson, R. C. (1997). Octopus dofleini and O. rubescens: Animal husbandry. In M. A. Lang \& F. G. Hochberg (Eds.), Proceedings of the workshop on fishery and market potential of octopus in California (pp. 141-149). Washington, DC: Smithsonian Institution.

Anderson, R. C. (2005). How smart are octopuses? Coral Magazine, 2, 44-48.

Anderson, R. C., \& Martin, A. W. (2002). An interview on octopuses with Cecil A. Brosseau (1919-1992). The Festivus, 34, 67-87.

Anderson, R. C., \& Mather, J. A. (2007). The packaging problem: Bivalve prey selection and prey entry techniques of the octopus (Enteroctopus dofleini). Journal of Comparative Psychology, 121, 300-305.

Angermeier, W. F., \& Dassler, K. (1992). Inhibitory learning and memory in the lesser octopus (Eledone cirrhosa). Bulletin of the Psychonomic Society, 30, 309-310.

Boal, J. G. (2006). Social recognition: A top-down view of cephalopod behaviour. Vie et Milieu, 56, 69-79.

Boivin, X., Garel, J. P., Mante, A., \& LeNeindre, P. (1998). Beef calves react differently to different handlers according to the test situation and their previous interactions with their caretaker. Applied Animal Behaviour Science, 55, 245-257.

Boyle, P. R. (1983). Ventilation rate and arousal in the octopus. Journal of Experimental Marine Biology and Ecology, 69, 129-136.

Boysen, S. T. (1994). Individual differences in the cognitive abilities of chimpanzees. In R. W. Wrangham, W. C. McGrew, F. B. M. de Waal, \& P. G. Heltne (Eds.), Chimpanzee cultures (pp. 335-350). Cambridge, MA: Harvard University Press.

Carlson, B. A., \& Delbeek, J. (1999). Cephalopod husbandry: Progress and problems. 1999 AZA annual conference proceedings. Baltimore, MD: American Zoo and Aquarium Association.

Chase, R., \& Wells, M. K. (1986). Chemotactic behavior in Octopus. Journal of Comparative Physiology, Series A, 158, 375.

Coss, R. G., \& Goldthwaite, R. O. (1995). The persistence of old designs for perception. In N. S. Thompson. (Ed.), Perspectives in Ethology (vol. 11, pp. 83-148). New York, NY: Plenum.

Cott, H. B. (1940). Adaptive coloration in animals. New York, NY: Oxford University Press.

Crancher, P., King, M. G., Bennett, A., \& Montgomery, R. B. (1972). Conditioning of a free operant in Octopus cyaneus Gray. Journal of the Experimental Analysis of Behavior, 17, 359-362.

Davis, H. (2002). Prediction and preparation: Pavlovian implications of research animals discriminating among humans. ILAR Journal Online, 43, 1-12.

Davis, H. (2007a). Discrimination between humans by cockroaches. In M. Bekoff (Ed.), Encyclopedia of human-animal relationships (pp. 174-177). San Francisco, CA: Greenwood. 
Davis, H. (2007b). Discrimination between humans by gentoo penguins (Pygoceli papua papualellsworthii). In M. Bekoff (Ed.), Encyclopedia of human-animal relationships (pp. 179-183). San Francisco, CA: Greenwood.

Davis, H. (2007c). Discrimination between humans by honeybees, In M. Bekoff (Ed.), Encyclopedia of human-animal relationships (pp. 183-186). San Francisco, CA: Greenwood.

Davis, H., \& Balfour, D. (1992). The inevitable bond. Cambridge, UK: Cambridge University Press.

Dews, P. B. (1959). Some observations on an operant in the octopus. Journal of the Experimental Analysis of Behaviour, 2, 57-63.

Fiorito, G., \& Scotto, P. (1992). Observational learning in Octopus vulgaris. Science, 256, 545- 547.

Hanlon, R. T., \& Messenger, J. B. (1996). Cephalopod behaviour. Cambridge, UK: Cambridge University Press.

Hochner, B., Shamrat, T., \& Fiorito, G. (2006). The octopus: A model for a comparative analysis of the evolution of learning and memory mechanism. Biological Bulletin, 210, 308-317.

Hvorecny, L. M., Gradowski, J. L., Blakeslee, C. J., Simmons, T. L., Roy, P. R., Brooks, ... Boal, J. G. (2007). Octopuses (Octopus bimaculoides) and cuttlefishes (Sepia pharaonis) can conditionally discriminate. Animal Cognition, 10, 449-459.

Koba, Y., \& Tanida, H. (2001). How do miniature pigs discriminate between people? Discrimination between people wearing coveralls of the same color. Applied Animal Behaviour Science, 73, 45-58.

Leite, T. S., \& Mather, J. A. (2008). A new approach to octopuses' body pattern analysis: A framework for taxonomy and behavioral studies. American Malacological Bulletin, 24, 31-41.

Lorenz, K. (1952). King Solomon's ring. New York, NY: Crowell.

Marzluff, J. M., \& Angell, T. (2005). In the company of crows and ravens. New Haven, CT: Yale University Press.

Mather, J. A. (1991). Navigation by spatial memory and use of visual landmarks in octopuses. Journal of Comparative Physiology, 168, 491-497.

Mather, J. A. (1992). Interactions of juvenile Octopus vulgaris with scavenging and territorial fishes. Marine Behaviour and Physiology, 19, 175-182.

Mather, J. A. (1995). Cognition in cephalopods. Advances in the Study of Behaviour, 24, 316-353.

Mather, J. A. (2008). Cephalopod consciousness: Behavioural cognition. Conscious Cognition, 1, 37-48.

Mather, J. A., \& Anderson, R. C. (1993). Personalities of octopuses (Octopus rubescens). Journal of Comparative Psychology, 107, 336-340.

Mather, J. A., \& Anderson, R. C. (1999). Exploration, play, and habituation in Octopuses (Octopus dofleini). Journal of Comparative Psychology, 113, 333-338.

Mather, J. A., \& Anderson, R. C. (2007). Ethics and invertebrates: A cephalopod perspective. Diseases of Aquatic Organisms, 75, 119-129.

Moynihan, M., \& Rodaniche, A. E. (1982). The behavior and natural history of the Caribbean reef squid (Sepioteuthis sepioidea). Advances in Ethology, 25, 1-151.

Muntz, R. A., \& Gwyther, J. (1988). Visual acuity in Octopus pallidus and Octopus australis. Journal of Experimental Biology, 134, 119-129.

Packard, A., \& Sanders, G. D. (1971). Body patterns of Octopus vulgaris and maturation of the response to disturbance. Animal Behaviour, 19, 780-790.

Papini, M. R., \& Bitterman. M. E. (1991). Appetitive conditioning in Octopus cyanea. Journal of Comparative Psychology, 105, 107-114.

Rousing, T., Ibsen, B., \& Sørenson, J. T. (2005). A note on: On-farm testing of the behavioural response of group-housed calves toward humans; test-retest and inter-observer reliability and effect of familiarity of test person. Applied Animal Behaviour Science, 94, 237-243.

Rybarczyk, P., Koba, Y., Rushen, J., Tanida, H., \& de Passillé, A. M. (2001). Can cows discriminate people by their faces? Applied Animal Behaviour Science, 74, 175-189. 
Sinn, D. L., Perrin, N. A., Mather, J. A., \& Anderson, R. C. (2001). Early temperamental traits in an octopus (Octopus bimaculoides). Journal of Comparative Psychology, 115, 351-364.

Soproni, K., Miklosi, A., Csanyi, V., \& Topal, J. (2001). Comprehension of human communicative signs in pet dogs (Canis familiaris). Journal of Comparative Psychology, 115, 122-126.

Sutherland, N. S., \& Carr, A. E. (1963). The visual discrimination of shape by Octopus: The effects of stimulus size. The Quarterly Journal of Experimental Psychology, 15, 225-235.

Warren, L. R., Schieier, M. E., \& Riley, D. A. (1974). Colour changes of Octopus rubescens during attacks on unconditioned and conditioned stimuli. Animal Behaviour, 22, 211-219.

Wells, M. J. (1978). Octopus-physiology and behaviour of an advanced invertebrate. London, UK: Chapman \& Hall.

Wells, M. J., O'Dor, R. K., Mangold, K., \& Wells, J. (1983). Diurnal changes in activity and metabolic rate in Octopus vulgaris. Marine Behaviour and Physiology, 9, 275-287.

Young, J. Z. (1956). Visual responses by octopus to crabs and other figures before and after training. Journal of Experimental Biology, 33, 709-729.

Zar, J. H. (1996). Biostatistical analysis (3rd ed.). Upper Saddle River, NJ: Prentice Hall. 